\title{
Formation of zero-valent iron in iron-reducing cultures of Methanosarcina barkeri
}

\author{
Haitao Shang ${ }^{1 *}$, Mirna Daye ${ }^{1}$, Orit Sivan ${ }^{2}$, Caue S. Borlina ${ }^{1}$, Nobumichi Tamura ${ }^{3}$, \\ Benjamin P. Weiss ${ }^{1}$ and Tanja Bosak ${ }^{1}$ \\ ${ }^{1}$ Department of Earth, Atmospheric and Planetary Science, Massachusetts Institute of Technology, \\ Cambridge, MA, USA \\ ${ }^{2}$ Department of Geological and Environmental Sciences, Ben Gurion University of the Negev, Beer \\ Sheva, Israel \\ ${ }^{3}$ Advanced Light Source, Lawrence Berkeley National Laboratory, Berkeley, CA, USA \\ *Email: hts@mit.edu
}

\begin{abstract}
Methanogenic archaea have been shown to reduce iron from ferric [Fe(III)] to ferrous [Fe(II)] state, but minerals that form during iron reduction by different methanogens remain to be characterized. Here, we show that zero-valent iron (ZVI) minerals, ferrite $[\alpha-\mathrm{Fe}(0)]$ and austenite $[\gamma$ - $\mathrm{Fe}(0)]$, appear in the X-ray diffraction spectra minutes after the addition of ferrihydrite to the cultures of the methanogenic archaeon Methanosarcina barkeri (M. barkeri). M. barkeri cells and redox-active, non-enzymatic soluble organic compounds in organic-rich spent culture supernatants can promote the formation of ZVI; the latter compounds also likely stabilize ZVI. Methanogenic microbes that inhabit organic- and $\mathrm{Fe}(\mathrm{III})$-rich anaerobic environments may similarly reduce oxidized iron to $\mathrm{Fe}(\mathrm{II})$ and ZVI, with implications for the preservation of paleomagnetic signals during sediment diagenesis and potential applications in the protection of iron metals against corrosion and in the green synthesis of ZVI.
\end{abstract}

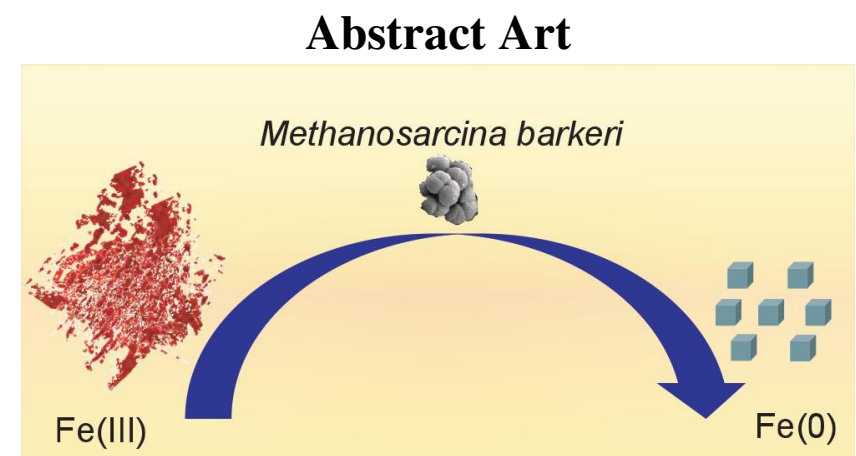

\section{Introduction}

30

31

32

33

34

35

Microorganisms mediate numerous redox transformations of iron in natural environments and couple the biogeochemical cycles of iron, carbon, oxygen, sulfur, nitrogen and other elements [14]. In soils and sediments, microbes can utilize ferric iron [Fe(III)] as the electron acceptor for dissimilatory iron reduction $[1,4,5]$. The reduction of $\mathrm{Fe}(\mathrm{III})$ produces ferrous iron $[\mathrm{Fe}(\mathrm{II})]$ that can be incorporated into different $\mathrm{Fe}(\mathrm{II})$-containing minerals such as magnetite [6,7], vivianite $[8,9]$ and siderite $[10,11]$. The formation of specific mineral phases is thought to depend on $\mathrm{pH}$, electron 
donors, $p \mathrm{CO}_{2}$ and other environmental factors [11].

Methanosarcina barkeri (M. barkeri), a coccoid methanogen, can grow on methanol, acetate and carbon dioxide/hydrogen $[12,13]$. The growth physiology of $M$. barkeri depends on the redox potential of the ambient environment: this microbe is able to survive high redox-potential conditions by generating its own low potential environment [14]. When M. barkeri produces methane $\left(\mathrm{CH}_{4}\right)$ with hydrogen gas $\left(\mathrm{H}_{2}\right)$ as the electron donor, it uses several electron carriers with low redox-potentials such as ferredoxin $\left(E^{0^{\prime}}=-500 \mathrm{mV}\right)$, coenzyme $\mathrm{F}_{420}\left(E^{0^{\prime}}=-360 \mathrm{mV}\right)$, coenzyme $\mathrm{B}\left(E^{0^{\prime}}=-140 \mathrm{mV}\right)$ and methanophenazine $\left(E^{0^{\prime}}=-165 \mathrm{mV}\right)$ [15]. These enable $M$. barkeri to reduce a range of oxidized compounds including ferrihydrite $\left[\mathrm{FeOOH}(\mathrm{am}) \rightarrow \mathrm{Fe}(\mathrm{II}), E^{0^{\prime}}=-50 \mathrm{mV}\right.$ [16]] into products with rather low reduction potentials. M. barkeri was shown to reduce amorphous [17-19] and crystalline [20,21] Fe(III) to Fe(II). Some of these studies also reported the formation of iron minerals such as magnetite [19] and vivianite [20]. However, only mineral phases that contain $\mathrm{Fe}$ (III) and/or Fe(II) have been reported, although other minerals, such as ilmenite, were hypothesized as well [17].

The low redox-potential environments where $M$. barkeri grows and persists may support the formation of other iron phases with low reduction potential, such as zero-valent iron (ZVI) [Fe(III) $+3 e^{-} \rightarrow \mathrm{Fe}(0), E^{0^{\prime}}=-37 \mathrm{mV}$ [22]]. ZVI is unstable in most surface environments because it is easily oxidized to $\mathrm{Fe}(\mathrm{II})$ or $\mathrm{Fe}(\mathrm{III})$ by both abiotic [23] and biological [24-27] reactions in a process known as iron corrosion. The reverse process - that is, the reduction of oxidized iron to ZVI - has also been observed in some abiotic reactions [28-31]. One example is the formation of $\mathrm{Fe}(0)$ in awaruite, a nickel and iron-containing alloy, in serpentinizing environments [31]. Several studies have also reported the reduction of Fe(III) in aqueous tea-leaf extracts to ZVI [32-34]. However, to the best of our knowledge, only one study reported the presence of small X-ray diffraction peaks of $\mathrm{Fe}(0)$ in microbial enrichment cultures of Geobacter sulfurreducens and Shewanella denitrificans that grew on ochre pigment [35].

Here, we explore the biomineralization of iron in low-potential environments that support microbial methanogenesis. This is done by characterizing minerals that form in iron-reducing cultures of $M$. barkeri and exploring mechanisms that produce and stabilize these minerals. Our results demonstrate the formation of titanomagnetite (or magnetite) and ZVI in active $M$. barkeri cultures and spent culture supernatants. The ability of $M$. barkeri to reduce oxidized iron to its metallic state may influence the cycling of nutrients and toxins in the environments, with potential applications in the protection against iron corrosion and in the green synthesis of ZVI.

\section{Materials and Methods}

\subsection{Cell Incubation}

M. barkeri (DSM 800) was obtained from Deutsche Sammlung von Mikroorganismen und Zellkulturen (DSMZ, Braunschweig, Germany). All serum bottles (160 mL) were autoclaved at $120{ }^{\circ} \mathrm{C}$ for 30 mins. Media were prepared according to modified medium recipe (Oregon Collection of Methanogens Medium for Methanogens [17]) (Supporting Information, Table S1). The medium contained either a low organic content $(1.0 \mathrm{~g} / \mathrm{L}$ of $50 / 50 \mathrm{wt} \%$ yeast extract and casitone, DIFCO) or a high organic content $(4.0 \mathrm{~g} / \mathrm{L}$ of $50 / 50 \mathrm{wt} \%$ yeast extract and casitone, DIFCO). Organic-free medium was prepared according to the same recipe, but without yeast extract and casitone. The media were titrated with a saturated $\mathrm{NaHCO}_{3}$ solution to $\mathrm{pH}$ 6.8. All media were prepared anaerobically, filter sterilized and added into the autoclaved serum bottles. 
90

91

92

93

94

95

96

97

98

99

100

101

102

103

104

105

106

107

108

109

110

111

112

113

114

115

116

117

118

119

120

121

122

123

M. barkeri cannot grow in the presence of $\mathrm{O}_{2}$, so the vacuum-vortex technique [36] was used to generate anaerobic conditions in the serum bottles. Gas mixture of $\mathrm{H}_{2} / \mathrm{CO}_{2}(80 \% / 20 \%)$ was added into serum bottles as the headspace atmosphere. Each $160 \mathrm{~mL}$ serum bottle contained $50 \mathrm{~mL}$ of liquid and $110 \mathrm{~mL}$ of headspace gas. The final pressure of headspace atmosphere was $100 \mathrm{kPa}$. Either Ti(III)-citrate (2.56 mM final concentration) or L-cysteine $(0.5 \mathrm{mM}$ final concentration) were used as reducing agents. Sulfide was not used as a reducing agent to avoid reactions with iron species and the formation of sulfide minerals. Preliminary experiments used different final concentrations of $\mathrm{Ti}(\mathrm{III})$-citrate $(0.85 \mathrm{mM}, 2.56 \mathrm{mM}$ and $7.67 \mathrm{mM})$ and found that $2.56 \mathrm{mM}$ Ti(III)-citrate was optimal for $M$. barkeri to grow and produce $\mathrm{CH}_{4}$. All cultures and controls were incubated at $37^{\circ} \mathrm{C}$.

\subsection{Experimental Design}

The experimental design is summarized in Table 1. Initially, we explored the biomineralization in $M$. barkeri cultures in the presence of ferrihydrite as a function of: (1) the content of organic additives in medium, (2) the timing of ferrihydrite addition, and (3) the composition of headspace gas in serum bottles. The $M$. barkeri inocula for all experiments were grown in the medium with $1 \mathrm{~g} / \mathrm{L}$ organic additives, these cultures were inoculated at 1:10 v/v into media that contained either $1 \mathrm{~g} / \mathrm{L}$ or $4 \mathrm{~g} / \mathrm{L}$ organic additives for growth and/or iron-reduction experiments. Most experiments described in what follows used $1 \mathrm{~g} / \mathrm{L}$ of these additives (yeast extract and casitone), a fourfold reduction relative to $4 \mathrm{~g} / \mathrm{L}$ in the original recipe [17]. Poorly crystalline ferrihydrite was prepared by titrating $\mathrm{FeCl}_{3}$ with $10 \mathrm{~N} \mathrm{NaOH}$ to $\mathrm{pH} 7$ to a final concentration of $7.5 \mathrm{mM}$ of ferrihydrite. Before the addition of ferrihydrite, the headspaces of triplicate $M$. barkeri cultures and triplicate sterile controls were flushed by $\mathrm{N}_{2} / \mathrm{CO}_{2}(80 \% / 20 \%)$ for 1 hour. To test if the headspace gas composition influences the precipitation of $\mathrm{Fe}(0)$, the headspaces of additional serum bottles with triplicate $M$. barkeri cultures or sterile media were not flushed to remove $\mathrm{H}_{2}$ and $\mathrm{CH}_{4}$. Aqueous $\mathrm{FeCl}_{3}$ ( $7.5 \mathrm{mM}$ final concentration) was added to the $M$. barkeri cultures to test the influence of different iron sources on the production of $\mathrm{Fe}(0)$.

Precipitates formed in M. barkeri cultures and sterile controls were sampled 30 mins, 28 days and 42 days after the addition of ferrihydrite. X-ray powder diffraction (XRD) and microfocused X-ray diffraction ( $\mu \mathrm{XRD}$ ) were used to characterize the mineral phases in the precipitates. Scanning electron microscopy (SEM) was used to observe the morphology of $M$. barkeri cells, minerals and characterize the association of cells and minerals. Energy-dispersive $\mathrm{X}$-ray spectroscopy (EDS) was used to determine the elemental composition of solids in the cultures. The redox state of iron was measured by X-ray photoelectron spectroscopy (XPS). The concentrations of $\mathrm{Fe}(\mathrm{II})$ were quantified by ferrozine assay [36]. The composition of headspace gases was characterized using gas chromatography.

To test the effects of soluble electron donors on the reduction of iron from ferric to metallic state, we separated $M$. barkeri cells and supernatants before the addition of ferrihydrite. This procedure consisted of the following steps: (1) cells were separated from medium by filtration using $0.1 \mu \mathrm{m}$ pore-size filters (glass microfiber, Cole Parmer, IL, USA), (2) spent supernatants were placed into clean, autoclaved and anaerobic serum bottles, (3) cells were washed with anoxic nanopure water, (4) cells were transferred into fresh organic-free medium in autoclaved and anaerobic serum bottles, (5) headspaces were flushed by $\mathrm{N}_{2} / \mathrm{CO}_{2}(80 \% / 20 \%)$ for 1 hour, and (6) ferrihydrite was added to the serum bottles that contained either filtered spent supernatants or 
124 cells in fresh organic-free medium. All steps in this procedure were performed using the sterile 125 technique in an anaerobic glove box. To ascertain that the separation process did not influence 126 the physiology of M. barkeri, procedure control cultures contained cells that were added back to 127 the filtered spent supernatants after the filtration and before the addition of ferrihydrite.

128

129

To determine whether any transient mineral phases formed in the early stages of these $1301 \mathrm{~min}, 5 \mathrm{mins}, 10 \mathrm{mins}$ and $30 \mathrm{mins}$ after the addition of ferrihydrite. After 30 mins, the 131 precipitates were sampled for analysis every 14 days until 42 days after the addition of 132 ferrihydrite. Iron concentrations were measured at each sampling point. 
Table 1: Experimental Design

\begin{tabular}{|c|c|c|c|c|c|c|c|c|c|}
\hline \multicolumn{2}{|c|}{ \# Bottle } & M.barkeri & Fe(III) Source & Addition of $\mathrm{Fe}$ (III) & Headspace & Organics & Reductant & Separation & Heating \\
\hline \multicolumn{2}{|c|}{$1,2,3$} & Inoculated & Ferrihydrite & Exponential phase & $\mathrm{N}_{2} / \mathrm{CO}_{2}$ & $1.0 \mathrm{~g} / \mathrm{L}$ & Ti(III)-citrate & No & No \\
\hline \multicolumn{2}{|c|}{$4,5,6$} & Inoculated & Ferrihydrite & Stationary phase & $\mathrm{N}_{2} / \mathrm{CO}_{2}$ & $1.0 \mathrm{~g} / \mathrm{L}$ & Ti(III)-citrate & No & No \\
\hline \multicolumn{2}{|c|}{$7,8,9$} & Inoculated & Ferrihydrite & Exponential phase & $\mathrm{CH}_{4} / \mathrm{H}_{2} / \mathrm{CO}_{2}$ & $1.0 \mathrm{~g} / \mathrm{L}$ & Ti(III)-citrate & No & No \\
\hline $\begin{array}{c}10, \\
12\end{array}$ & 11, & Inoculated & Ferrihydrite & Stationary phase & $\mathrm{CH}_{4} / \mathrm{H}_{2} / \mathrm{CO}_{2}$ & $1.0 \mathrm{~g} / \mathrm{L}$ & Ti(III)-citrate & No & No \\
\hline \multicolumn{10}{|c|}{15} \\
\hline \multicolumn{10}{|c|}{18} \\
\hline \multicolumn{9}{|c|}{21} & No \\
\hline \multicolumn{7}{|c|}{24} & Ti(III)-citrate & No & No \\
\hline $\begin{array}{c}25 \\
27\end{array}$ & 26 & Sterile control & Ferrihydrite & - & $\mathrm{N}_{2} / \mathrm{CO}_{2}$ & $4.0 \mathrm{~g} / \mathrm{L}$ & Ti(III)-citrate & No & No \\
\hline $\begin{array}{c}28 \\
30\end{array}$ & 29 , & Inoculated & Ferrihydrite & Exponential phase & $\mathrm{N}_{2} / \mathrm{CO}_{2}$ & $1.0 \mathrm{~g} / \mathrm{L}$ & L-cysteine & No & No \\
\hline $\begin{array}{c}31 \\
33\end{array}$ & 32 & Sterile control & Ferrihydrite & - & $\mathrm{N}_{2} / \mathrm{CO}_{2}$ & $1.0 \mathrm{~g} / \mathrm{L}$ & L-cysteine & No & No \\
\hline $\begin{array}{c}34 \\
36\end{array}$ & 35 & Procedure control & Ferrihydrite & Exponential phase & $\mathrm{N}_{2} / \mathrm{CO}_{2}$ & $1.0 \mathrm{~g} / \mathrm{L}$ & Ti(III)-citrate & Yes & No \\
\hline $\begin{array}{c}37 \\
39\end{array}$ & 38 & Inoculated & Ferrihydrite & Exponential phase & $\mathrm{N}_{2} / \mathrm{CO}_{2}$ & organic-free & Ti(III)-citrate & Yes & No \\
\hline $\begin{array}{c}40 \\
42\end{array}$ & 41, & Filtrate (no cells) & Ferrihydrite & Exponential phase & $\mathrm{N}_{2} / \mathrm{CO}_{2}$ & $1.0 \mathrm{~g} / \mathrm{L}$ & Ti(III)-citrate & Yes & No \\
\hline $\begin{array}{c}43 \\
45\end{array}$ & 44 & Inoculated & Ferrihydrite & Exponential phase & $\mathrm{N}_{2} / \mathrm{CO}_{2}$ & organic-free & Ti(III)-citrate & Yes & Yes \\
\hline $\begin{array}{c}46 \\
48\end{array}$ & 47 & Filtrate (no cells) & Ferrihydrite & Exponential phase & $\mathrm{N}_{2} / \mathrm{CO}_{2}$ & $1.0 \mathrm{~g} / \mathrm{L}$ & Ti(III)-citrate & Yes & Yes \\
\hline $\begin{array}{c}49 \\
51\end{array}$ & 50 & Sterile control & Ferrihydrite & - & $\mathrm{N}_{2} / \mathrm{CO}_{2}$ & organic-free & Ti(III)-citrate & Yes & No \\
\hline $\begin{array}{c}52 \\
54\end{array}$ & 53 & Sterile control & Ferrihydrite & - & $\mathrm{N}_{2} / \mathrm{CO}_{2}$ & organic-free & Ti(III)-citrate & Yes & Yes \\
\hline
\end{tabular}




\begin{tabular}{|c|c|c|c|c|c|c|c|c|c|}
\hline $\begin{array}{c}55, \\
57\end{array}$ & 56 & Inoculated & $\mathrm{FeCl}_{3}$ & Exponential phase & $\mathrm{N}_{2} / \mathrm{CO}_{2}$ & $1.0 \mathrm{~g} / \mathrm{L}$ & Ti(III)-citrate & No & No \\
\hline $\begin{array}{c}58 \\
60\end{array}$ & 59 , & Sterile control & $\mathrm{FeCl}_{3}$ & - & $\mathrm{N}_{2} / \mathrm{CO}_{2}$ & $1.0 \mathrm{~g} / \mathrm{L}$ & Ti(III)-citrate & No & No \\
\hline
\end{tabular}


To explore the roles of extracellular and cell-associated enzymes in the reduction of ferrihydrite and the production of $\mathrm{Fe}(0)$, we followed above procedure [steps (1) to (4)] to separate M. barkeri cells and supernatants, flushed the headspaces by $\mathrm{N}_{2} / \mathrm{CO}_{2}(80 \% / 20 \%)$ for 1 hour, heated all serum bottles and organic-free sterile controls to $120^{\circ} \mathrm{C}$ for 4 hours and allowed them to cool down for 5 hours to room temperature $\left(20^{\circ} \mathrm{C}\right)$ before the addition of ferrihydrite.

Because some reducing agents such as $\mathrm{Ti}(\mathrm{III})$-citrate were previously hypothesized to influence the redox transformations of iron [17], we also tested the importance of this reductant for the formation of $\mathrm{Fe}(0)$. This was done by replacing $\mathrm{Ti}(\mathrm{III})$-citrate by L-cysteine $(0.5 \mathrm{mM}$ final concentration) as the reducing agent in the medium with low organic content $(1 \mathrm{~g} / \mathrm{L})$.

\subsection{Analytical Methods}

The concentrations of headspace gases, including $\mathrm{CH}_{4}, \mathrm{CO}_{2}$ and $\mathrm{H}_{2}$, were measured in triplicates by a Shimadzu GC-2014 gas chromatograph configured with a packed column (Carboxen-1000, 5'x 1/8', Supelco, Bellefonte, Pennsylvania, USA). The temperature was set to $140{ }^{\circ} \mathrm{C}$, and argon was used as the carrier gas. $\mathrm{CH}_{4}$ and $\mathrm{CO}_{2}$ were measured by the methanizer-flame ionization detector (FID) and $\mathrm{H}_{2}$ was measured by the thermal conductivity detector (TCD). The concentrations of gases were calculated from their partial pressures based on the standards calibrated with the SCOTTY Specialty Gas (T237-14, Sigma-Aldrich Corporation, MO, USA).

The concentrations of $\mathrm{Fe}(\mathrm{II})$ were measured by a microplate reader (BioTek, Synergy ${ }^{\mathrm{TM}}$ 2, VT, USA) at $562 \mathrm{~nm}$ in $200 \mu \mathrm{L}$ triplicate samples of mixtures obtained by mixing $1 \mathrm{~mL}$ subsamples of media that had been filtered through $0.2 \mu \mathrm{m}$ pore-size filters (Acrodisc $25 \mathrm{~mm}$ syringe filter, PALL Corporation, MA, USA) and fixed immediately with $100 \mu \mathrm{L}$ ferrozine solution. This solution was prepared by dissolving $0.01 \mathrm{M}$ ferrozine (FW 492.47, 97\%) in $0.1 \mathrm{M}$ ammonium acetate $\left(\mathrm{CH}_{3} \mathrm{COONH}_{4}, 99.99 \%\right)$ solution [37]. The concentrations of Fe(II) were determined using standards that contained solutions of $\mathrm{Fe}$ (II) with known concentrations from 0 to $0.36 \mathrm{mM}$ and analytical standard deviation of $\sim 0.001 \mathrm{mM}$. The reported errors in this paper are the standard deviations from the measured triplicates.

Precipitated minerals were characterized using XRD on an X'Pert PRO diffractometer (PANalytical manufacturer) equipped with an X'Celerator detector. The precipitates were collected by centrifugation at 14,000 rpm for $5 \mathrm{mins}$, smeared on zero diffraction disk (23.6 mm diameter x 2.0 $\mathrm{mm}$ thickness, Si Crystal, MTI Corporation, CA, USA) and dried in an anaerobic glove box. The samples were analyzed inside an anaerobic dome to maintain the anoxic conditions during the XRD analyses. The XRD patterns were measured in reflection mode with nickel-filtered copper $\mathrm{K} \alpha$ radiation $(\lambda=1.5406 \AA$ ) as the X-ray source. The X-ray energy and the wavelength, respectively, were set with a $\mathrm{Si}(\mathrm{III})$ double-crystal monochromator to be, respectively, $10 \mathrm{keV}$ and $1.2404( \pm 0.001)$ $\AA$. The $2 \theta$ angle ranged from $3^{\circ}$ to $90^{\circ}$ with a scanning step of $0.008^{\circ}$. The fixed counting time was set as $1000 \mathrm{~s}$ at $45 \mathrm{kV}$ and $40 \mathrm{~mA}$. Wavelength and $2 \theta$ calibrations were maintained by frequently measuring intensity data from an aluminum foil (transmission geometry) or LaB6 powder (reflection geometry). A platinum-coated toroidal focusing mirror with a step size of $0.04^{\circ}$ was used to reject $\mathrm{X}$ rays with the energies $>11 \mathrm{keV}$ and to produce a focused beam of dimensions $1 \mathrm{~mm} \times 4 \mathrm{~mm}$. Transmission data were corrected for $\theta$-dependent attenuation of incident and scattered X-rays. XRD spectra were analyzed with the High Score Plus program (version 4.5, Malvern Panalytical Incorporated, Netherlands). Rietveld fitting method [38] was used to refine crystals and to determine the atomic coordinates and lattice parameters of different mineral phases. Iron phases were determined according to the Miller indices (hkl) that denote planes orthogonal to the reciprocal crystal lattice vector. The presence of superstructure reflections (hkls of 111 and 200) at $2 \theta=42.94^{\circ}$ and $50.01^{\circ}$ 
indicated austenite $[\gamma$ - $\mathrm{Fe}(0)]$ with the d-spacing of $2.104 \AA$. The presence of superstructure reflections (hkls of 110,200 and 211 ) at $2 \theta=45.32^{\circ}, 66.03^{\circ}$ and $83.72^{\circ}$ indicated ferrite $[\alpha-\mathrm{Fe}(0)]$ with the $\mathrm{d}-$ spacing of $1.999 \AA$. Rietveld fitting was also used to quantify the phases in the fitting phase mixture and determine the percentages of austenite and/or ferrite.

Minerals were also analyzed using in situ synchrotron $\mu$ XRD at the Advanced Light Source at the beamline 12.3.2. Samples were collected on site and the sample paste was loaded into transmission sample XRD cells. The transmission synchrotron diffraction data were collected using a DECTRIS Pilatus $1 \mathrm{M}$ hybrid pixel area detector placed at $2 \theta=35^{\circ}$ at approximately $170 \mathrm{~mm}$ from the sample. The 4-bounce monochromator was set to $10 \mathrm{keV}(\lambda=1.239842 \AA)$. The sample geometry with respect to the incident beam and the detector was calibrated using $\mathrm{Al}_{2} \mathrm{O}_{3}$ powder. The 2D diffraction patterns were analyzed and integrated along the azimuthal direction into 1D diffractograms using the X-ray microdiffraction analysis software (version 6, XMAS) developed at the Advanced Light Source for the beamline 12.3.2, and MATLAB R2017a.

XPS was performed on a K-Alpha ${ }^{\mathrm{TM}} \mathrm{X}$-ray photoelectron spectrometer (Thermo Fisher Scientific, MA, USA). All samples were fractured in high vacuum $\left(3 \times 10^{-8}\right.$ Torr $)$ in the Kratos outer pressure chamber and then moved directly into the main XPS measurement chamber. An incident monochromatic X-ray beam from the Al K Alpha target $(10 \mathrm{kV}, 10 \mathrm{~mA})$ was focused on a $0.4 \mathrm{~mm} \times$ $0.3 \mathrm{~mm}$ area at a $45^{\circ}$ angle with respect to the sample surface. The electron energy analyzer perpendicular to the sample surface was operated with a pass energy of $50 \mathrm{eV}$ to obtain XPS spectra at a $0.1 \mathrm{eV}$ step size and a dwell time of $50 \mathrm{~ms}$. Each peak was scanned 15 times. To ensure representative data from heterogeneous samples, we probed a total of 50-70 points per sample. XPS data were treated and analyzed using CasaXPS curve resolution software package. Spectra were best fit after Shirley background subtractions by non-linear least squares CasaXPS curve resolution software package. Gaussian/Lorentzian (G/L) contributions to the line shapes were numerically convoluted using a Voigt function. The different XPS lines with sets of Gaussian and Lorentzian peaks were empirically fitted with different standards corresponding to different oxidation states $\mathrm{Fe}(0), \mathrm{Fe}(\mathrm{II})$ and $\mathrm{Fe}(\mathrm{III})$.

Thermomagnetic measurements were attempted to quantify the amount of ZVI in the samples. This was done by heating the samples to a temperature at which only ZVI contributes significantly to the magnetization. In particular, if the samples are heated up to the titanomagnetite Curie temperature $\left(<580{ }^{\circ} \mathrm{C}\right)$, the saturation magnetic moment at this temperature could be used to infer the amount of ZVI given knowledge of ZVI's temperature-dependent saturation magnetization [equation (2) in [39]]. With this goal, we sampled the precipitates from exponential-phase M. barkeri cultures incubated in high organic medium $(4 \mathrm{~g} / \mathrm{L})$ under a $\mathrm{N}_{2} / \mathrm{CO}_{2}$ headspace and placed $\sim 0.1 \mathrm{~mL}$ samples on top of a MicroSense quartz perpendicular sample holder (blank saturation magnetic moment of $4 \times 10^{-9} \mathrm{Am}^{2}$ ). The samples were left to dry inside an anaerobic glove box. We then acquired saturation magnetization thermomagnetic measurements using an ADE model 1660 vibrating sample magnetometer with an applied field of $1 \mathrm{~T}$ at intervals of $50{ }^{\circ} \mathrm{C}$ from room temperature up to $350{ }^{\circ} \mathrm{C}$ (in the laboratory of C. Ross in the Department of Materials Science and Engineering at MIT). Both heating and cooling curves were obtained to check for thermochemical alteration.

SEM was used to image microbial and mineral morphologies, and microbe-mineral associations. Scanning electron micrographs were acquired by a Zeiss Merlin GEMINI II column high-resolution scanning electron microscope (Carl Zeiss microscopy, CA, USA) equipped with a field gun emission and EDS (EDAX detector; EDAX, NJ, USA) operating at an accelerating voltage of 5-15 kV, probe current of $100 \mathrm{pA}$ and a working distance of $8.5 \mathrm{~mm}$. On-axis in-lens secondary electron (SE-mode) detector was used during imaging. The samples were fixed by $0.2 \mathrm{M}$ sodium cacodylate, $0.1 \% \mathrm{CaCl}_{2}$ 
and $2.5 \%$ glutaraldehyde in anaerobic water for 2-3 days at $4{ }^{\circ} \mathrm{C}$. The fixed samples were washed by $0.1 \mathrm{M}$ sodium cacodylate, followed by a wash in nanopure water. After washing, the samples were dehydrated with a series of ethanol-water solutions consisting of 30\% (20 mins), 50\% (20 mins), $70 \%$ (20 mins), 80\% (20 mins), 90\% (20 mins) and 100\% (20 mins) of 200 proof ethanol. After air-drying, the samples were mounted on double-sided carbon tape and coated with a thin layer $5 \mathrm{~nm}$ of Au/Pd or $10 \mathrm{~nm}$ of carbon before imaging using Hummer V sputter coater. EDS spectra were treated and analyzed using TEAM ${ }^{\mathrm{TM}}$ EDS software (version 2.0, EDAX Incorporated, NJ, USA) and Microsoft Excel 2016.

\section{Results}

Because ferrihydrite is a common form of Fe(III) in the environment [40], we used this phase as the solid electron acceptor in most of our experiments. We explored the formation of iron minerals in $M$. barkeri cultures by adding ferrihydrite to the cultures initially grown on $\mathrm{H}_{2} / \mathrm{CO}_{2}$. The concentration of $\mathrm{Fe}(\mathrm{II})$ in cultures increased with the incubation time due to the continuous reduction of ferrihydrite [Figure 1(a)], regardless of the growth phase and the composition of the headspace gases (Table 1). The color of the medium darkened with the incubation time and black precipitates formed [Figure $1(b)]$.

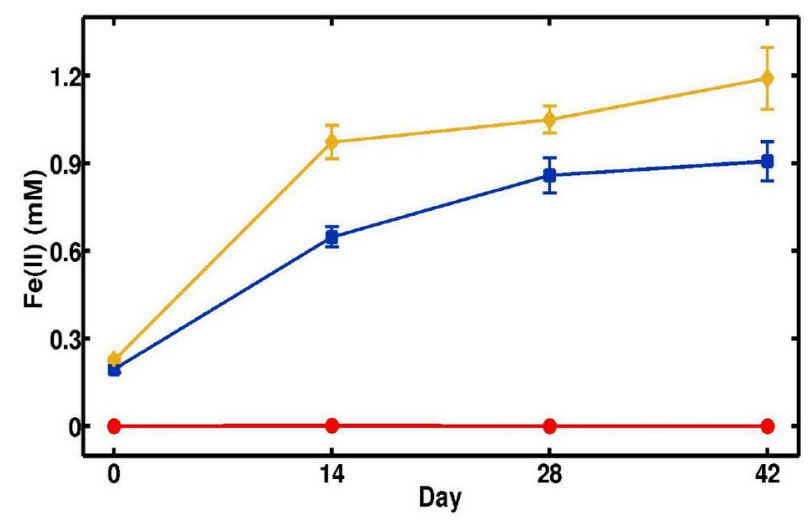

(a)

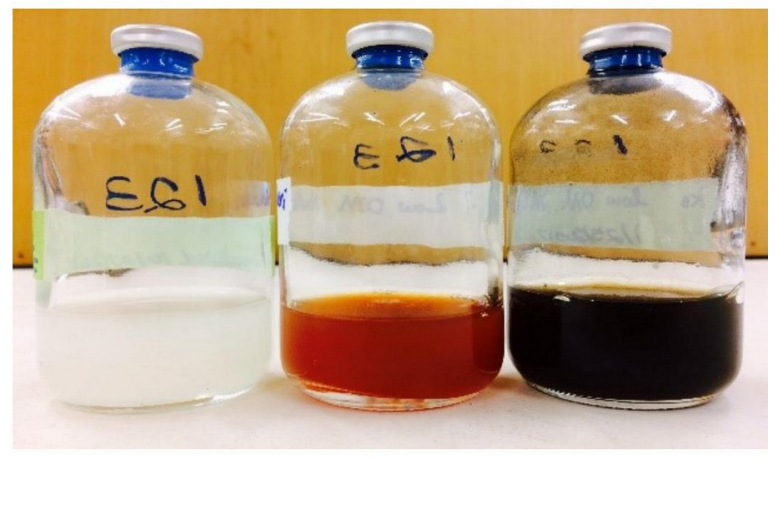

(b)

Figure 1: Representative changes of Fe(II) concentration and color in iron-reducing cultures of $M$. barkeri and sterile controls. The headspaces of all cultures and controls shown here contained $\mathrm{N}_{2} / \mathrm{CO}_{2}$. The medium in all M. barkeri cultures and controls contained $1.0 \mathrm{~g} / \mathrm{L}$ of yeast extract and casitone. (a) $\mathrm{Fe}(\mathrm{II})$ concentration. Blue line and squares show measurements from $M$. barkeri cultures to which ferrihydrite was added in exponential phase. Yellow line and diamonds show measurements from M. barkeri cultures to which ferrihydrite was added in stationary phase. Red line and circles show that $\mathrm{Fe}(\mathrm{II})$ was not produced in sterile controls. Each time point shows the average concentration from triplicate bottles and the error bars show the standard deviation. (b) Representative color changes in cultures and sterile controls. Left (white) bottle contains $M$. barkeri without ferrihydrite, the middle (reddish) bottle is the sterile control and the right (black) bottle contains M. barkeri incubated with ferrihydrite for 28 days.

Precipitates were first sampled from cultures and sterile controls 30 mins after the addition of ferrihydrite. Figure 2 shows representative XRD data. At this time point, halite $(\mathrm{NaCl})$ and rutile $\left(\mathrm{TiO}_{2}\right)$ were present in the XRD spectra of both M. barkeri cultures and sterile controls. This showed that rutile formed by the abiotic oxidation of $\mathrm{Ti}$ (III)-citrate. Fe(II)-containing titanomagnetite $\left(\mathrm{Ti}_{2} \mathrm{Fe}_{3} \mathrm{O}_{4}\right)$ was observed in $M$. barkeri cultures at all sampling time points, but never in sterile controls. Surprisingly, the $M$. barkeri cultures at 30 mins also contained ferrite $[a-\mathrm{Fe}(0)]$ with d-spacing of $1.999 \AA$. Because the $a-\mathrm{Fe}(0)$ and halite peaks overlapped, we used the Rietveld refinement to show that $a-\mathrm{Fe}(0)$ was indeed present (Supporting Information, Table S2). After 28 days, the peaks of austenite $[\gamma$ - $\mathrm{Fe}(0)]$ with 
d-spacing of $2.104 \AA$ appeared in M. barkeri cultures. After 42 days, the peaks of $a$-Fe( 0$)$ disappeared from the XRD spectra, but the peaks of $\gamma$ - $\mathrm{Fe}(0)$ were still present. $\gamma$ - $\mathrm{Fe}(0)$ was also detected by the $\mu X R D$ (Supporting Information, Figure S1) and XPS (Supporting Information, Figure S2). To confirm that $\mathrm{Fe}(0)$ was not present in the original iron source, we characterized ferrihydrite samples by XRD and found no $\mathrm{Fe}(0)$ peaks. These observations showed that ferrihydrite-reducing $M$. barkeri produced titanomagnetite and mediated the precipitation of $\mathrm{Fe}(0)$. The same phases were detected in $M$. barkeri cultures in stationary phase (Supporting Information, Figure S3), under a $\mathrm{CH}_{4} / \mathrm{H}_{2} / \mathrm{CO}_{2}$ atmosphere (Supporting Information, Figure S4) and in the high-organic (4 g/L) medium (Supporting Information, Figure S5). $a$ - $\mathrm{Fe}(0)$ was absent from sterile controls at all times, whereas some low-intensity XRD peaks - either a single peak or two small peaks - matching $\gamma$-Fe(0) appeared in some spectra of sterile controls 28 days after the addition of ferrihydrite Supporting Information, Figure S4 and S5). These $\mathrm{Fe}(0)$ peaks were detected in two-thirds of all independent experiments under these conditions and were not detectable 42 days after the addition of ferrihydrite. In contrast, $\gamma$-Fe( 0$)$ was always identifiable by two distinct peaks in the XRD spectra of $M$. barkeri cultures and remained detectable 42 days after the addition of ferrihydrite. If $\gamma$ - $\mathrm{Fe}(0)$ was indeed present in sterile controls, then some components in the sterile media can contribute to the formation of $\mathrm{Fe}(0)$, but are not effective at stabilizing it over long incubation times.

\section{2}
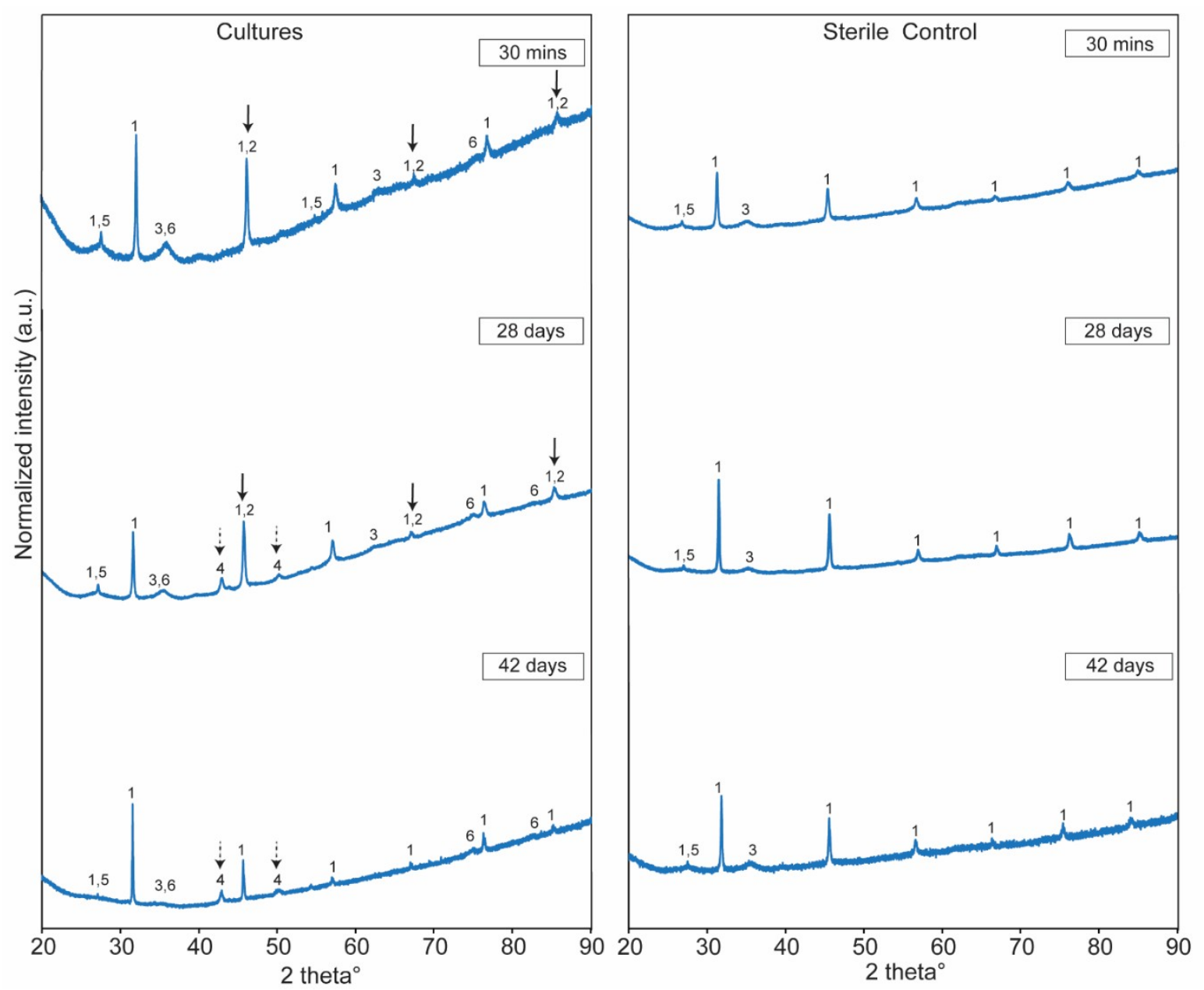

Figure 2: XRD spectra of minerals sampled from M. barkeri cultures (left column) and sterile controls (right column). The medium was reduced by $\mathrm{Ti}(\mathrm{III})$-citrate and contained $1 \mathrm{~g} / \mathrm{L}$ of organic additives. The headspace gas was replaced by $\mathrm{N}_{2} / \mathrm{CO}_{2}$ 
the addition of ferrihydrite. XRD peak assignments: (1) Halite (NaCl); (2) Ferrite $[\alpha-\mathrm{Fe}(0)]$; (3) Ferrihydrite $\left(\mathrm{Fe}_{2} \mathrm{O}_{3}\right)$; (4)

Austenite $[\gamma$ - $\mathrm{Fe}(0)]$; (5) Rutile $\left(\mathrm{TiO}_{2}\right)$; (6) Titanomagnetite $\left(\mathrm{Ti}_{2} \mathrm{Fe}_{3} \mathrm{O}_{4}\right)$.

The stoichiometry of the reduction of $\mathrm{Fe}(\mathrm{III})$ to $\mathrm{Fe}(\mathrm{II})$ and $\mathrm{Fe}(0)$ remains to be elucidated. Under our experimental conditions, titanomagnetite formed readily, so we were not able to separate various solid phases, quantify the relative amounts of reduced iron present in titanomagnetite and ZVI and compare them to the concentrations of Fe(II) in the solution. Thermomagnetic measurements were used to determine the quantities of magnetite and $\mathrm{Fe}(0)$ (Supporting Information, Figure S6); however, these attempts were not successful due to the production of new magnetic materials and changes in magnetic mineralogy during the laboratory heating cycle.

SEM imaging revealed morphological changes of $M$. barkeri and the morphologies of minerals that formed during the incubation with ferrihydrite. Initially, the rounded M. barkeri cells had smooth surfaces and formed large aggregates (Supporting Information, Figure S7). After the addition of ferrihydrite, the diameter of $M$. barkeri cells and the sizes of cell aggregates decreased with the incubation time and the cells exhibited wrinkled surfaces [Figure 3(A)]. Cubic minerals with the EDS spectra consistent with ZVI phases and spherical minerals with the EDS spectra consistent with titanomagnetite were not associated with cells or cell aggregates [Figure 3(B) and (C)], suggesting that the formation of these minerals did not require direct cell-mineral contact.

To understand whether the precipitation of $\mathrm{Fe}(0)$ was a function of the $\mathrm{Fe}(\mathrm{III})$ source, we added aqueous $\mathrm{FeCl}_{3}(7.5 \mathrm{mM}$ final concentration) to the triplicate cultures of exponential-phase M. barkeri and triplicate sterile controls. All bottles contained medium with a low content $(1 \mathrm{~g} / \mathrm{L})$ of organic additives and was reduced by Ti(III)-citrate. All headspaces were replaced by $\mathrm{N}_{2} / \mathrm{CO}_{2}$ before the addition of $\mathrm{FeCl}_{3}$. Again, halite and rutile peaks were present in the XRD spectra of both M. barkeri cultures and sterile controls (Supporting Information, Figure S8) at all time points. The precipitates in M. barkeri cultures also contained titanomagnetite, but $a$ - $\mathrm{Fe}(0)$ peaks only appeared in these cultures 42 days after the addition of $\mathrm{FeCl}_{3}$. ZVI was absent from the sterile controls at all time points. Thus, ZVI formed much more slowly when $\mathrm{FeCl}_{3}$ was used instead of ferrihydrite as the source of ferric iron.
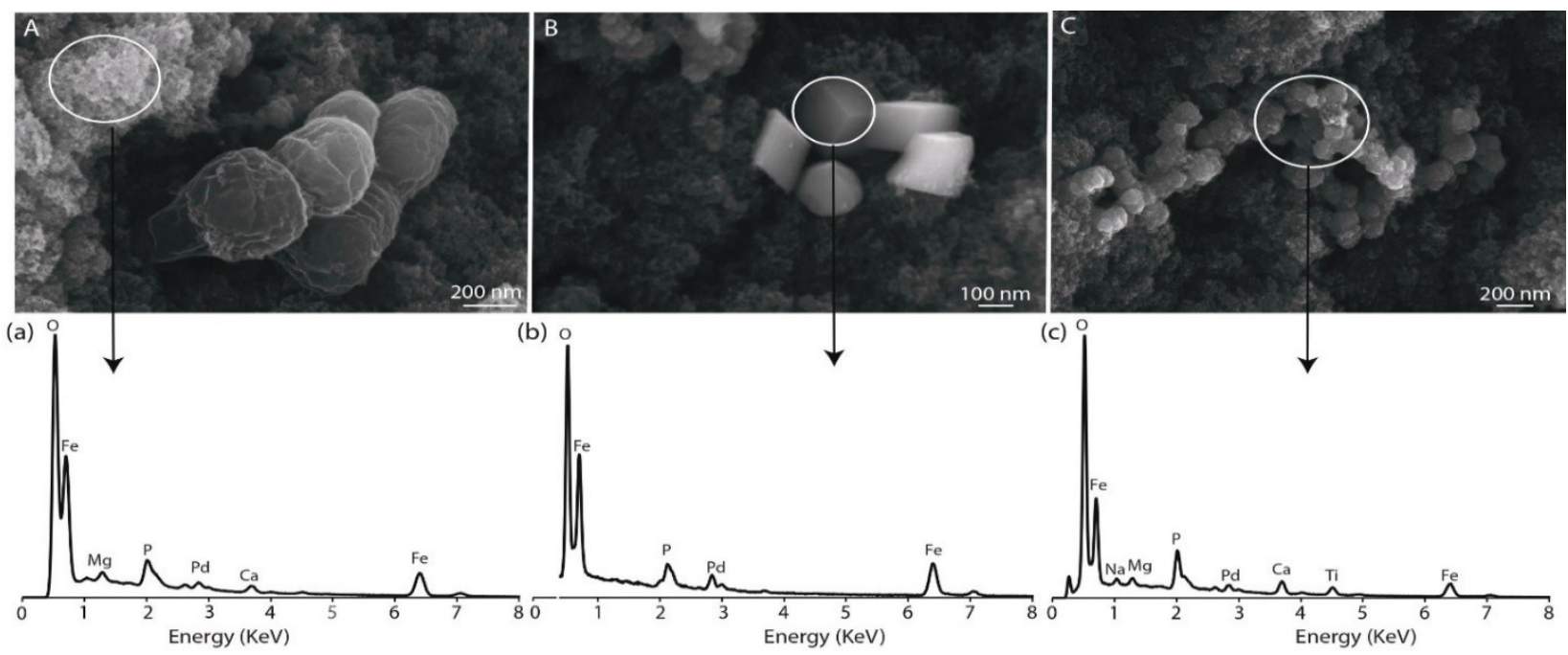

Figure 3: SEM images and EDS spectra of M. barkeri cultures and minerals 28 days after the addition of ferrihydrite. (A) Wrinkled surfaces of M. barkeri. (a) EDS spectrum of amorphous ferrihydrite. The peak of phosphorus (labeled as P) was also present in the EDS spectra of ferrihydrite from sterile controls. (B) Cubic-shaped ZVI. (b) EDS spectrum of (B). (C) Titanomagnetite. (c) EDS spectrum of (C). 
322

cysteine instead of $\mathrm{Ti}(\mathrm{III})$-citrate to the medium with a low organic content $(1 \mathrm{~g} / \mathrm{L})$. The headspace was replaced by $\mathrm{N}_{2} / \mathrm{CO}_{2}$ before the addition of ferrihydrite to exponential-phase cultures and sterile controls. The XRD spectra (Supporting Information, Figure S9) showed $\mathrm{Fe}(0)$, magnetite and halite in the solids from the cysteine-reduced cultures. As expected, rutile and titanomagnetite were absent due to the lack of Ti(III). Thus, the formation of $\mathrm{Fe}(0)$ did not depend on the presence of $\mathrm{Ti}(\mathrm{III})$ as the reducing agent. The XRD spectra of cysteine-reduced sterile controls (Supporting Information, Figure S9) contained $\alpha$ $\mathrm{Fe}(0)$ at 28 days and $\gamma$ - $\mathrm{Fe}(0)$ phase at 42 days after the addition of ferrihydrite. This observation was consistent with the previously reported ability of L-cysteine to precipitate and stabilize ZVI [41].

We hypothesized that both $M$. barkeri cultures and dissolved electron donor(s) reduced iron [17]. To understand the relative importance of either mechanism in the reduction of ferric iron and the formation of ZVI, we separated $M$. barkeri cells in exponential phase from the liquid medium by filtration. The organic-free medium in sterile serum bottles was inoculated by these filter-separated cells. Equal volumes of organic-containing spent culture supernatants were added to three clean, autoclaved and anaerobic sterile serum bottles. The headspaces of all bottles were then flushed by $\mathrm{N}_{2} / \mathrm{CO}_{2}$ before the addition of ferrihydrite (Table 1). To confirm that the filtration did not influence the physiology of M. barkeri, we recombined the filtered M. barkeri cells and the filtered supernatants in a separate procedure control (Table 1). The final Fe(II) concentration in this procedure control was 0.86 $\mathrm{mM}$. This recovered around $95 \%$ of the $\mathrm{Fe}(\mathrm{II})$ concentration $-0.91 \mathrm{mM}-$ measured in a previous experiment where the cells were not separated from the supernatants [Figure 1(a)] and showed that the filtration and separation of cells from the spent culture supernatants did not influence the physiology of M. barkeri. Iron reduction occurred both in the organic-free medium with M. barkeri cells and in filtersterilized spent supernatants that lacked cells (Figure 4), but cells and organic additives reduce iron by different mechanisms and at different rates. Namely, the concentration of $\mathrm{Fe}$ (II) in the organic-free medium inoculated by $M$. barkeri increased to about $0.3 \mathrm{mM}$ during the first 30 mins after the addition of ferrihydrite (Figure 4) and remained unchanged afterwards. In contrast, the filtered supernatants contained only $0.013 \mathrm{mM} \mathrm{Fe}(\mathrm{II})$ at 30 min after the addition of ferrihydrite, but the concentration of Fe(II) increased to $0.52 \mathrm{mM}$ after 28 days (Figure 4). These differences between organic-free $M$. barkeri cultures and cell-free spent culture supernatants were accompanied by different trends in the formation and stabilization of ZVI. 


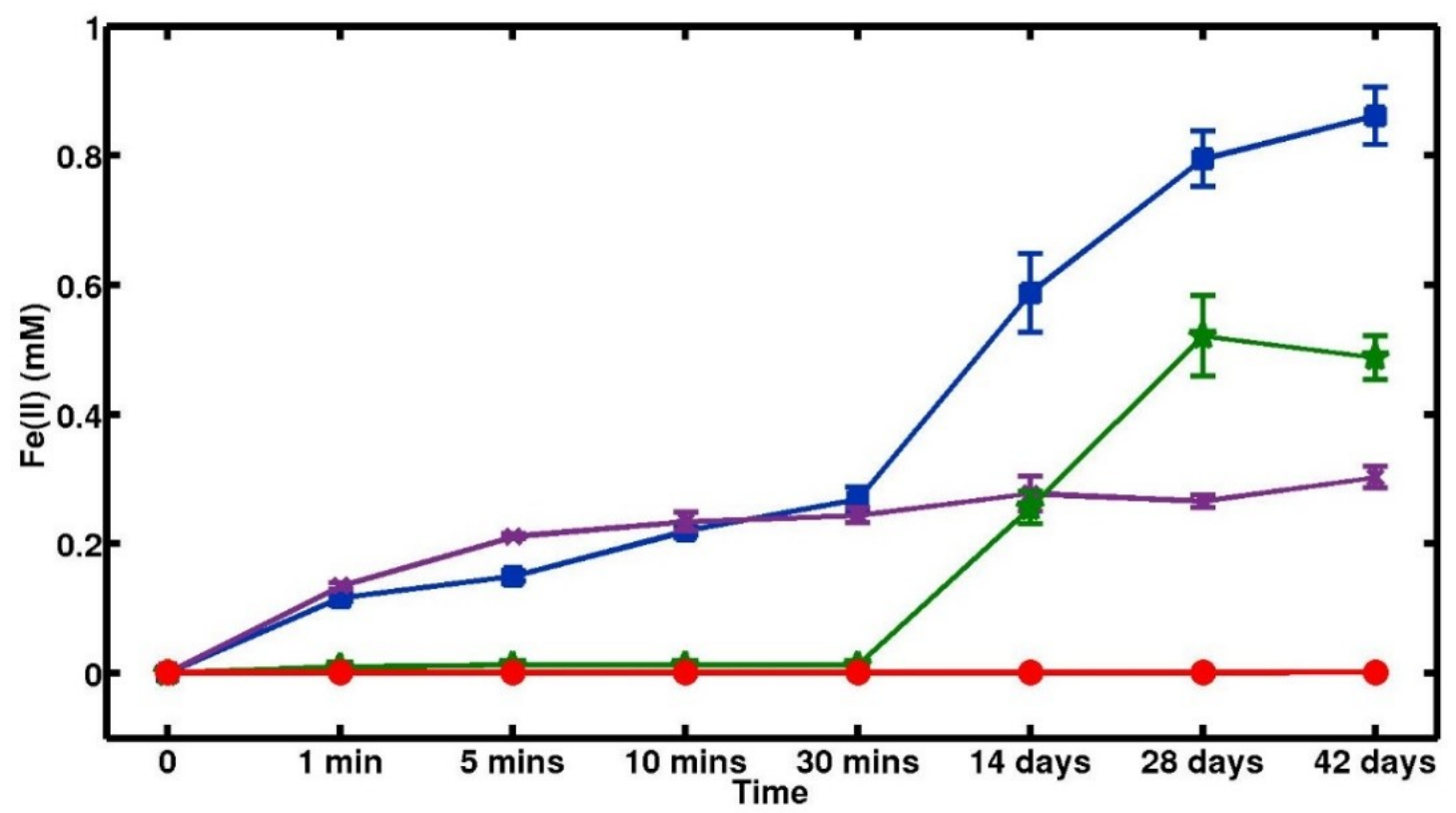

Figure 4: The change of Fe(II) concentration in: organic-free medium with cells (purple line and crosses), filter-sterilized spent supernatants (green line and stars), sterile control (red line and circles) and procedure control that contained recombined filtered cells and spent supernatants (blue line and squares). Each point shows the average concentration from triplicate bottles and the error bars show the standard deviation.

Previous studies identified green rust, an unstable precursor of several iron oxide minerals such as magnetite and hematite, as a transient phase during iron reduction under both biotic and abiotic experimental conditions [42-44]. To look for the presence of similar short-lived mineral phases in $M$. barkeri cultures, we sampled the precipitates from the organic-free medium inoculated by cells, filtersterilized spent supernatants and organic-free sterile controls at $1 \mathrm{~min}, 5 \mathrm{mins}, 10 \mathrm{mins}$ and $30 \mathrm{mins}$ after the addition of ferrihydrite. After that time, the samples were collected every 14 days. In short, we did not detect green rust in any of the analyzed precipitates, but did confirm various observations from our previous experiments. $\mathrm{Fe}(0)$ minerals were absent from organic-free sterile controls at all time points (Supporting Information, Figure S10). In the organic-free medium inoculated by cells (Figure 5), peaks of $\alpha-\mathrm{Fe}(0)$ appeared in the precipitates at $1 \mathrm{~min}$ after the addition of ferrihydrite. Their intensity decreased 

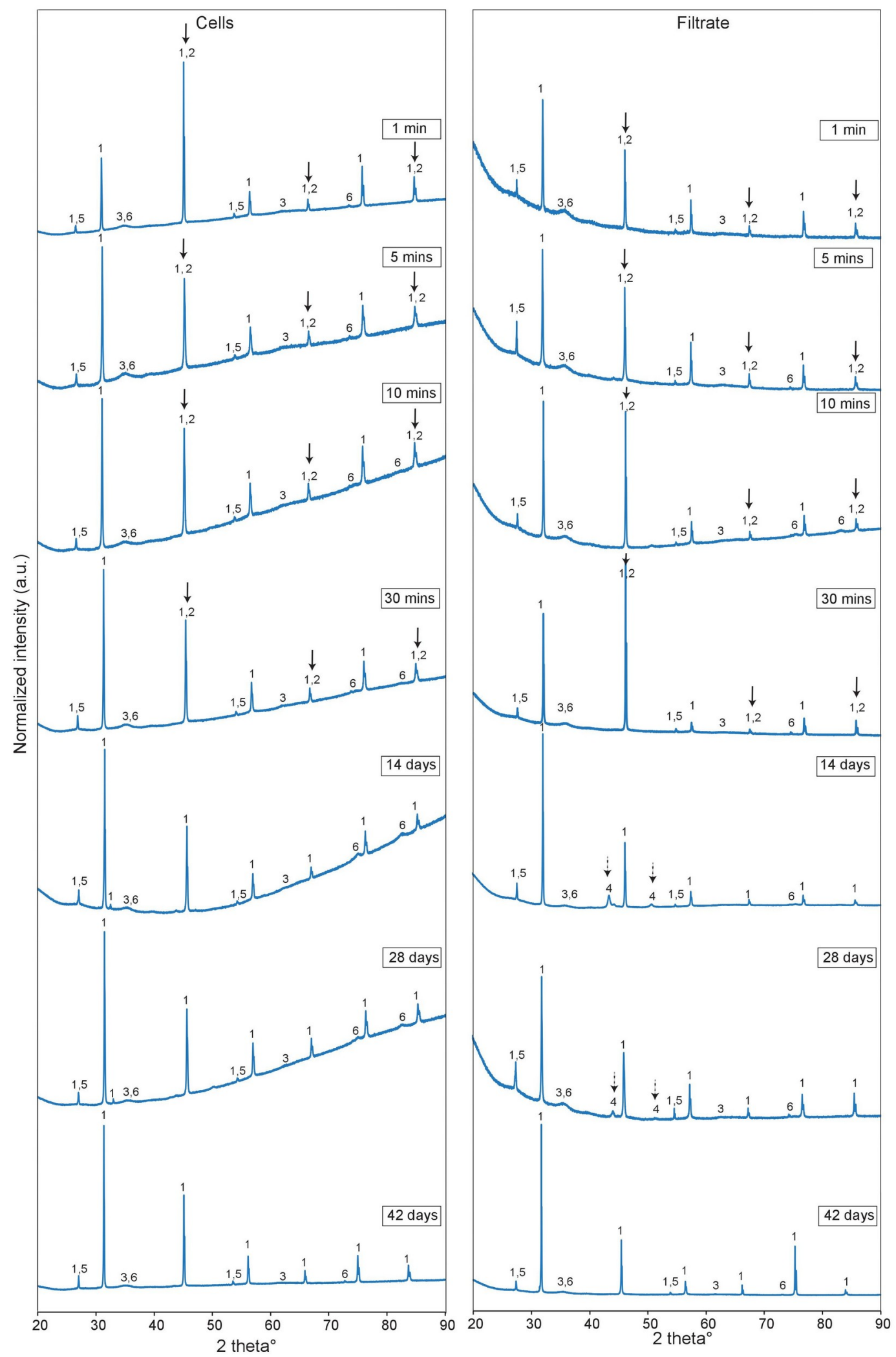

Figure 5: XRD spectra of minerals sampled from serum bottles that contained cells in organic-free medium (left column) and filter-sterilized spent supernatants (right column). The medium was reduced by Ti(III)-citrate and the headspace gas was replaced by $\mathrm{N}_{2} / \mathrm{CO}_{2}$ before the addition of ferrihydrite. The solids were sampled at $1 \mathrm{~min}, 5 \mathrm{mins}$, and $10 \mathrm{mins}, 30 \mathrm{mins}, 14$ days, 28 days and 42 days after the addition of ferrihydrite. XRD peak assignments: (1) Halite (NaCl); (2) Ferrite [ $\alpha$ - $\mathrm{Fe}(0)]$; (3) Ferrihydrite $\left(\mathrm{Fe}_{2} \mathrm{O}_{3}\right)$; (4) Austenite $\left[\gamma\right.$-Fe(0)]; (5) Rutile $\left(\mathrm{TiO}_{2}\right)$; (6) Titanomagnetite $\left(\mathrm{Ti}_{2} \mathrm{Fe}_{3} \mathrm{O}_{4}\right)$. 
over the first 30 mins of the experiment to below the detection limit after 14 days. Comparatively, smaller $\alpha$ - $\mathrm{Fe}(0)$ peaks appeared in the XRD spectra of the spent supernatants 1 min after the addition of ferrihydrite and their intensity increased at 5, 10, and 30 mins (Figure 5), $\alpha-\mathrm{Fe}(0)$ in the spent supernatants transformed to a different phase of ZVI - $\gamma$-Fe( $(0)$ - after 14 days, but none of the $\mathrm{Fe}(0)$ phases were detectable in 42-day-old samples. Again, because the $a$ - $\mathrm{Fe}(0)$ and halite peaks overlapped, the Rietveld refinement was used to demonstrate the presence of $\alpha$ - $\mathrm{Fe}(0)$ (Supporting Information, Table S3). These experiments revealed the very rapid formation of $\mathrm{Fe}(0)$ when either M. barkeri cells were present in the organic-free medium or organic compounds were present in the cell-free spent supernatants. The stabilization of $\mathrm{Fe}(0)$ phases for more than 30 days required both cells and organic additives. We detected no $\mathrm{Fe}(0)$ in the organic-free sterile controls, but found tentative peaks in the sterile controls amended by organic compounds 28 days after the addition of ferrihydrite (Supporting Information, Figure S4 and S5). Hence, yeast extract and casitone may promote the formation of ZVI, but are not sufficient for its stabilization.

Our results so far indicated that $M$. barkeri cells and soluble organic compounds both promoted the formation and stabilization of ZVI. To determine whether this process required some enzymatic activity, we characterized the precipitates from the heat-treated spent supernatants and the organic-free media inoculated by $M$. barkeri cells. Spent supernatants or organic-free M. barkeri cultures were prepared as described in the previous paragraphs (also see Section 2.2). Triplicate sealed serum bottles containing either separate were heated at $120^{\circ} \mathrm{C}$ in an oven for 4 hours and allowed to cool at room temperature for 5 hours before the addition of ferrihydrite. The heat-treated M. barkeri cultures reduced $0.007 \mathrm{mM}$ of $\mathrm{Fe}(\mathrm{III})$ to $\mathrm{Fe}$ (II) 30 mins after the addition of ferrihydrite; this concentration remained unchanged after 42 days (Supporting Information, Figure S11). The concentration of Fe(II) in heattreated spent supernatants increased from $0.005 \mathrm{mM}$ at $30 \mathrm{mins}$ after the addition of ferrihydrite to $0.313 \mathrm{mM}$ after 42 days (Supporting Information, Figure S11). These concentrations were $2.5 \%$ and $64.3 \%$ of the respective $\mathrm{Fe}(\mathrm{II})$ concentrations measured in culture separates that did not undergo heating (Figure 4). Thus, non-enzymatic redox-active compounds were responsible for around $37 \%$ of the total activity that reduced ferric to ferrous iron in M. barkeri cultures. This is consistent with a previous report, which measured $11 \%$ of this activity in unfiltered heat-treated cultures 14 days after the addition of ferrihydrite [17]. The heat treatment did not prevent ZVI from forming. The peaks of $\mathrm{Fe}(0)$ appeared in the XRD spectra from both heat-treated separates 30 mins after the addition of ferrihydrite (Supporting Information, Figure S12). These peaks disappeared after 28 days in the presence of heattreated M. barkeri cells (in organic-free medium), but were still detectable after 42 days in heat-treated spent supernatants. Given that ZVI was not detected in 42-day-old spent supernatants that did not undergo any heat treatment, the heat treatment appeared to have increased the persistence of ZVI in organic-containing medium.

\section{Discussion}

Various microorganisms, including M. barkeri, have been shown to reduce iron oxides and mediate the formation of different Fe(II)-containing minerals $[6-11,17,18]$. This work provides the first evidence that archaea can mediate the rapid precipitation of ZVI in the presence of Fe(III). The precipitation of $\mathrm{Fe}(0)$ requires the presence of soluble, redox-active compounds that can interact with ferric iron and stabilize ZVI and can occur in the absence of cells and enzymatic activity. At $37^{\circ} \mathrm{C}$, this reduced phase was stabilized over periods longer than one month only in the presence of both M. barkeri and soluble organic compounds.

The mechanism of electron transport during the formation of $\mathrm{Fe}(0)$ remains to be elucidated. The detection of ZVI in spent supernatants and the lack of spatial associations among M. barkeri cells and 
421 ferrihydrite, titanomagnetite and ZVI support the extracellular reduction of ferrihydrite to Fe(II) and 422 ZVI. Previous studies have proposed several mechanisms of extracellular electron transport between 423 microbes and minerals: (1) electrically conductive pili or nanowires, (2) chelating compounds that 424 reduce and solubilize Fe(III) minerals and (3) soluble electron carriers [2,17]. We did not observe any 425 pili or nanowires by SEM, so the last two mechanisms are more likely to occur under our experimental 426 conditions.

M. barkeri synthesizes several electron carriers with low redox potentials, including ferredoxin, coenzyme F420, coenzyme B and methanophenazine (Table 2) [15]. According to the Eh-pH diagram for the $\mathrm{Fe}-\mathrm{CO}_{2}-\mathrm{H}_{2} \mathrm{O}$ system $[45,46], \mathrm{ZVI}$ can be stable in the Eh range from about $-450 \mathrm{mV}$ to $-650 \mathrm{mV}$ at $\mathrm{pH}$ values 5-7 seen in our carbonate-buffered system. This is comparable to the redox potential of ferredoxin $(-500 \mathrm{mV})$ (Table 2), although the roles of this and other carriers remain to be tested. As stated previously, enzymatic activity cannot account for the rapid formation of ZVI by the heat-treated $M$. barkeri cells and spent supernatants. Furthermore, due to the poor solubility of methanophenazine in water and its strong association with cell membranes [47], we suspect that this compound is not critical for the formation of ZVI in spent supernatants or at a distance from M. barkeri cells.

Our experimental results do not directly link the formation of ZVI to the interactions between cellular metabolism and Fe cations. In fact, our observations suggest that M. barkeri cells and/or any cell-associated surface organics that are not removed during the washing procedure and/or the heat treatment can promote the formation of ZVI and that active metabolism is not essential. Potential electron donors for the reduction of ferric iron to ZVI in $M$. barkeri cultures include membraneassociated or water-soluble redox-active compounds such as enzymes, coenzymes or even amino acids such as L-cysteine. Although the tentative appearance of ZVI in a few organic-amended sterile controls suggested that the organic additives (yeast extract and casitone) might promote the production of ZVI, they were not effective at stabilizing it under our experimental conditions. Given that $\mathrm{Fe}(0)$ formed in the heat-treated organic-free cell cultures and heat-treated spent supernatants, a major contribution of heat-destabilized enzymes is also unlikely. Instead, the formation of ZVI depends primarily on nonenzymatic and soluble metabolites produced by $M$. barkeri in organic-replete media.

The long-term persistence of ZVI in $M$. barkeri cultures requires soluble organic compounds. In keeping with this, $\mathrm{Fe}(0)$ peaks persist longer in the XRD spectra of spent supernatants compared to those of the cells incubated in the organic-free medium (Figure 5). The metabolite(s) produced by $M$. barkeri may be similar to the ZVI-stabilizing L-cysteine [41]. Previous attempts to synthesize ZVI in an ecologically friendly manner have produced $\mathrm{Fe}(0)$ by adding $\mathrm{Fe}(\mathrm{III})$ as $\mathrm{FeNO}_{3}$ or $\mathrm{FeCl}_{3}$ to plant extracts [32,33]. The formation of ZVI in the presence of polyphenols from plant extracts contributed to the blackening of solutions [32,33] in a manner similar to that shown in [Figure 1(b)]. The $E^{0^{\prime}}$ of these compounds range from $300 \mathrm{mV}$ to $800 \mathrm{mV}$, which is higher compared to the potentials in M. barkeri cultures. It is unclear whether the cultures of $M$. barkeri contain phenolic compounds, but we speculate that the low redox potential in the methanogen cultures (Table 2) further facilitates the reduction of iron from ferric to metallic state and the stabilization of ZVI.

Table 2: Relevant redox half-reactions at $\mathrm{pH}=7$

\begin{tabular}{cc}
\hline \hline Possible Redox Half Reaction & $E^{0^{\prime}}(\mathrm{mV})$ \\
\hline Ferredoxin $($ ox $) \rightarrow$ Ferredoxin $(\mathrm{red})$ & $-500[15]$ \\
Coenzyme $\mathrm{F}_{420}(\mathrm{ox}) \rightarrow{\text { Coenzyme } \mathrm{F}_{420}(\mathrm{red})}$ & $-360[15]$ \\
Coenzyme B $(\mathrm{ox}) \rightarrow$ Coenzyme B (red) & $-140[15]$
\end{tabular}




\section{Environmental Implications}

471 Microbially mediated iron corrosion is a known natural process and a major industrial and engineering

472 concern [48-50]. Methanogenic archaea, sulfate reducing bacteria, acetogenic bacteria and nitrate reducing bacteria are all able to oxidize $\mathrm{Fe}(0)$ under anaerobic conditions [50]. Our results demonstrate that $M$. barkeri can mediate the reverse process, wherein Fe(III) in ferrihydrite is reduced and stabilized as ZVI. This expands the list of microbially mediated iron reduction reactions and biomineralization processes. In the light of our results, ZVI may form and become stabilized in reducing and organic-rich anaerobic environments. If ZVI produced in this manner can interact with other elemental cycles, it can be readily oxidized to $\mathrm{Fe}(\mathrm{II}) / \mathrm{Fe}(\mathrm{III})$ and therefore not detectable.

Biogenic magnetite is widespread in marine [51,52] and riverine sediments [19,53]. This mineral can be produced by different microorganisms including bacteria (e.g., magnetotactic bacteria [51,52], Geobacter [54,55] and Shewanella [56]), archaea (e.g., Methanosarcinaceae [19]) and fungi (e.g., Fusarium oxysporum and Verticillium sp. [57]). Recent studies have shown that electrically conductive substances such as magnetite, hematite and graphite facilitate direct interspecies electron transfer (DIET) $[19,54]$ and promote syntrophic cooperation in microbial communities [58-60]. For example, magnetite can enhance the electron transfer from G. sulfurreducens to T. denitrificans and facilitate nitrate reduction by $T$. denitrificans [58]. Magnetic minerals in deep sediments carry paleomagnetic information that can be altered by phase transformations during diagenesis [61,62]. Magnetite and ZVI produced by anaerobic microorganisms such as methanogens are examples of phases that can influence the paleomagnetic records. Ferrihydrite is ubiquitous in nature [40]; its delivery to reducing and organic-rich anaerobic environments may enable microbial precipitation of ZVI (i.e., a conductive and reactive material) that then promotes DIET in the communities of anaerobes $[63,64] . \mathrm{Fe}(0)$ peaks were not reported in the XRD spectra in the studies of DIET in the presence of microbial iron reduction [19, 55-57]. Their absence might indicate that the redox conditions or organic compounds in these studies did not support the formation and/or stabilization of ZVI or that the produced ZVI was oxidized during the processes of mineral characterization. Our experiments tested for $\mathrm{Fe}(0)$ production by $M$. barkeri only, so it remains to be seen whether ZVI formation by methanogens is a ubiquitous phenomenon.

The impact of exogenously added ZVI on the structure of microbial communities in aquifer sediments [65] and soils [66] is an area of active research. For example, several studies of pure cultures have reported that ZVIs are toxic to Escherichia coli [67,68], Dehalococcoides spp. [69] and Desulfosporosinus spp. [65,70]. Thus, ZVI particles produced naturally by M. barkeri or other methanogens may influence the ecology of anaerobic environments by inhibiting the growth of some microbes and promoting the growth of Fe(0)-resistant anaerobes (e.g., Raoultella planticola [71] and Alcaligenes eutrophus [72]). Previous studies have shown that the reduction of ferric to ferrous iron by methanogens can compete with methanogenesis $[17,18]$. Any ZVI particles produced by methanogenic archaea might also intersect with the biogeochemical cycles of carbon and sulfur by either enhancing [73,74] or inhibiting [75] methanogenesis and inhibiting biological sulfate reduction [65,70]. These results imply that the production of $\mathrm{Fe}(0)$ by methanogens may affect both the reduction of $\mathrm{CO}_{2}$ and the accumulation of $\mathrm{CH}_{4}$ in anaerobic environments and $\mathrm{CH}_{4}$-consuming microbes. In our experiments and other studies [17,18], methanogenesis was inhibited after the addition of ferrihydrite into the M. barkeri cultures. However, the main goal of our experiments was to characterize minerals in pure cultures of 
511 iron-reducing $M$. barkeri as a function of the reductants and cellular and enzymatic activity. Further

512 experiments are needed to determine the impact of ZVI formation on methanogenesis and the anaerobic 513 oxidation of $\mathrm{CH}_{4}$ in natural communities.

514 The microbially mediated production of ZVI may find industrial applications in metal protection 515 and green synthesis. Microorganisms can inhibit iron corrosion by several indirect mechanisms, such as 516 the formation of protective films and consumption of corrosive substances [47,76]. The reverse iron 517 corrosion in $M$. barkeri cultures shows that at least this microbe can form and stabilize ZVI in 518 anaerobic and organic-rich environments that receive labile forms of ferric iron such as ferrihydrite. 519 These conditions can be explored further to identify the range of chemical conditions and more 520 complex microbial communities that protect steel. Given that microbial methanogenesis is widespread 521 in various terrestrial or marine environments and industrial or water-treatment facilities [77-80], the 522 availability of methanogenic enrichments and organic-rich fluids from these systems should be 523 conducive to cost-effective green synthesis of ZVI.

524

\section{Acknowledgements}

526 We thank the current members of the Bosak laboratory, the Simons Foundation Collaboration on the 527 Origins of Life grants no. 327126 to T.B., NSF FESD grant no. 14-374 to T.B. and the MIT-Israel 528 program award no. 2629055 to T.B. and O.S. The NSF award number DMR-1419807 funded MIT 529 Center for Material Science and Engineering (part of Materials Research Science and Engineering 530 Center, NSF ECCS. award no. 1541959) and funded the Harvard University Center for Nanoscale 531 Systems (CNS), a member of the National Nanotechnology Coordinated Infrastructure Network 532 (NNCI). The DOE Office of Science User Facility under contract no. DE-AC02-05CH11231 supports 533 the Advanced Light Source and BI L12.3.2.

Supporting Information. Medium recipe; X-ray diffraction (XRD) spectra under different experimental conditions; Rietveld analyses of XRD spectra; micro-focused X-ray diffraction; thermomagnetic measurements; scanning electron microscope images; $\mathrm{Fe}(\mathrm{II})$ concentration measurements

\section{References}

[1] Weber, K. A.; Achenbach, L.A.; Coates, J. D. Microorganisms pumping iron: anaerobic microbial iron oxidation and reduction. Nature Reviews Microbiology 2006, 4, 752-764.

[2] Melton, E. D.;Swanner, E. D.;Behrens, S.; Schmidt, C.; Kappler, D. The interplay of microbially mediated and abiotic reactions in the biogeochemical Fe cycle. Nature Reviews Microbiology 2014, 12, 797-808.

[3] Konhauser, K. O.; Kappler, A.; Roden, E. E. Iron in microbial metabolisms. Elements 2011, 7 , 89-93.

[4] Fredrickson, J. K.; Gorby, Y. A. Environmental processes mediated by iron-reducing bacteria. Current Opinion in Biotechnology 1996, 7, 287-294.

[5] Luu, Y. S.; Ramsay, J. A. Review: Microbial mechanisms of accessing insoluble Fe(III) as an energy source. World Journal of Microbiology and Biotechnology 2003, 19, 215-225.

[6] Lovely, D. R.; Stolz, J. F.; Nord, G. L.; Phillips, E. J. P. Anaerobic production of magnetite by a dissimilatory iron-reducing microorganism. Nature 1987, 330, 252-254.

[7] Bell, P. E.; Mills, A. L.; Herman, J. S. Biogeochemical conditions favoring magnetite formation during anaerobic iron reduction. Applied and Environmental Microbiology 1987, 53, 2610-2616. 
[8] Liu, D.; Wang, H.; Dong, H.; Qiu, X.; Dong, X.; Cravotta III, C. A. Mineral transformations associated with goethite reduction by Methanosarcina barkeri. Chemical Geology 2011, 288, 53-60.

[9] Dong, H.; Kostka, J. E.; Kim, J. Microscopic evidence for microbial dissolution of smectite. Clays and Clay Minerals 2003, 51, 502-512.

[10] Kim, J.; Dong, H.; Seabaugh, J.; Newell, S. W.; Eberl, D. D. Role of microbes in the smectite-toillite reaction. Science 2004, 303, 830-832.

[11] Roh, Y.; Zhang, C. L.; Vali H.; Lauf, R. J.; Zhou, J.; Phelps, T. J. Biogeochemical and environmental factors in Fe biomineralization: magnetite and siderite formation. Clays and Clay Minerals 2003, 51, 83-95.

[12] Ferry, J. G. Methanogenesis: ecology, physiology, biochemistry \& genetics: Springer-Verlag, New York, NY, 2012.

[13] Jones, W. J.; Nagle Jr, D. P.; Whitman, W. B. Methanogens and the diversity of archaebacteria. Microbiological Reviews 1987, 51, 135-177.

[14] Fetzer, S.; Conrad, R. Effect of redox potential on methanogenesis by Methanosarcina barkeri. Archives of Microbiology 1993, 160, 108-113.

[15] Thauer, R. K.; Kaster, A. K.; Seedorf, H.; Buckel, W.; Hedderich, R. Methanogenic archaea: ecologically relevant differences in energy conservation. Nature Reviews Microbiology 2008, 6, 579-591.

[16] Wiedemeier T. H.; Rifai, H. S.; Newell, C. J.; Wilson, J. T. Natural attenuation of fuels and chlorinated solvents in the subsurface: John Wiley \& Sons, New York, NY, 1999.

[17] Sivan, O.; Shusta, S. S.; Valentine, D. Methanogens rapidly transition from methane production to iron reduction. Geobiology 2016, 14, 190-203.

[18] Van Bodegom, P. M.; Scholten, J. C. M.; Stams, A. J. M. Direct inhibition of methanogenesis by ferric iron. FEMS Microbiology Ecology 2004, 49, 261-268.

[19] Zheng, S.; Wang, B.; Liu, F.; Wang, O. Magnetite production and transformation in the methanogenic consortia from coastal riverine sediments. Journal of Microbiology 2017, 55, 862870.

[20] Liu, D.; Dong, H.; Bishop, M. E.; Wang, H.; Agrawal, A.; Tritschler, S.; Eberl, D. D.; Xie, S. Reduction of structural $\mathrm{Fe}(\mathrm{III})$ in nontronite by methanogen Methanosarcina barkeri. Geochimica et Cosmochimica Acta 2011, 75, 1057-1071.

[21] Bond, D. R.; Lovley, D. R. Reduction of Fe(III) oxide by methanogens in the presence and absence of extracellular quinones. Environmental Microbiology 2002, 4, 115-124.

[22] Vanysek, P. Electrochemical series: CRC Press, Boca Raton, FL, 2000.

[23] Revie, W. R. Corrosion and Corrosion Control: an introduction to corrosion science and engineering: John Wiley \& Sons, Hoboken, New Jersey, 2008.

[24] Enning D.; Garrelfs, J. Corrosion of iron by sulfate-reducing bacteria - new views of an old problem. Applied and Environmental Microbiology, 2014, 80, 1226-1236.

[25] Dinh, H. T.; Kuever, J.; Mußmann, M.; Hassel, A. W.; Stratmann, M.; Widdel, F. Iron corrosion by novel anaerobic microorganisms. Nature 2004, 427, 829-832.

[26] Daniels, L.; Belay, N.; Rajagopal, B. S.; Weimer, P. J. Bacterial methanogenesis and growth from $\mathrm{CO}_{2}$ with elemental iron as the sole source of electrons. Science 1987, 237, 509-511.

[27] Lee, W.; Characklis, W. G. Corrosion of mild steel under anaerobic biofilm. Corrosion 1993, 49, $186-199$.

[28] Pineau, A.; Kanari, N.; Gaballah, I. Kinetics of reduction of iron oxides by $\mathrm{H}_{2}$ : Part I: low temperature reduction of hematite. Thermochimica Acta 2006, 447, 89-100. 
602

603

604

605

606

607

608

609

610

611

612

613

614

615

616

617

618

619

620

621

622

623

624

625

626

627

628

629

630

631

632

633

634

635

636

637

638

639

640

641

642

643

644

645

646

647

[29] Pineau, A.; Kanari, N.; Gaballah, I. Kinetics of reduction of iron oxides by $\mathrm{H}_{2}$ : Part II: low temperature reduction of magnetite. Thermochimica Acta 2007, 456, 75-88.

[30] Chen, Y.; Chen, S.; Chen, Q.; Zhou, Z.; Sun, S. Electrochemical preparation of iron cuboid nanoparticles and their catalytic properties for nitrite reduction. Electrochimica Acta 2008, 53, 6938-6943.

[31] Klein F.; Bach, W. Fe-Ni-Co-O-S phase relations in peridotite-seawater interactions. Journal of Petrology 2009, 50, 37-59.

[32] Hoag, G. E.; Collins, J. B.; Holcomb, J. L.; Hoag, J. R.; Nadagouda, M. M.; Varma, R. S. Degradation of bromothymol blue by greener nano-scale zero-valent iron synthesized using tea polyphenols. Journal of Materials Chemistry 2009, 19, 8671-8677.

[33] Nadagouda, M. N.; Castle, A. B.; Murdock, R. C.; Hussain, S. M.; Varma, R. S. In vitro biocompatibility of nanoscale zero-valent iron particles (NZVI) synthesized using tea polyphenols. Green Chemistry 2010, 12, 114-122.

[34] Machado, S.; Pinto, S. L.; Grosso, J. P.; Nouws, H. P. A.; Albergaria, J. T.; Delerue-Matos, C. Green production of zero-valent iron nanoparticles using tree leaf extracts. Science of the Total Environment 2013, 445, 1-8.

[35] Rahman, P. K. S. M.; Bastola, S. Biological reduction of iron to the elemental state from ochre deposits of Skelton beck in northeast England. Frontiers in Environmental Science 2014, 2, 22, $1-8$.

[36] Wolfe, R. S.; Metcalf, W. W. A vacuum-vortex technique for preparation of anoxic solutions or liquid culture media in small volumes for cultivating methanogens or other strict anaerobes. Anaerobe 2010, 16, 216-219.

[37] Viollier, E.; Inglett, P. W.; Hunter, K. S.; Roychoudhury, A. N.; Van Cappellen, P. The ferrozine method revisited: $\mathrm{Fe}(\mathrm{II}) / \mathrm{Fe}(\mathrm{III})$ determination in natural waters. Applied Geochemistry 2000, 15, 785-790.

[38] Rietveld, H. M. A profile refinement method for nuclear and magnetic structures. Journal of applied Crystallography 1969, 2, 65-71.

[39] Garrick-Bethell, I.; Weiss, B. P. Kamacite blocking temperatures and applications to lunar magnetism. Earth Planetary Science Letter 2010, 294, 1-7.

[40] Jambor, J. L.; Dutrizac, J. E. Occurrence and constitution of natural and synthetic ferrihydrite, a widespread iron oxyhydroxide. Chemical Reviews 1998, 98, 2549-2586.

[41] Bagbi, Y.; Sarswat, A.; Tiwari, S.; Mohan, D.; Pandey, A.; Solanki, P. R. Synthesis of Lcysteine stabilized zero-valent iron (NZVI) nanoparticles for lead remediation from water. Environmental Nanotechnology, Monitoring \& Management 2017, 7, 34-45.

[42] Zachara, J. M.; Kukkadapu, R. K.; Fredrickson, J. K.; Gorby, Y. A.; Smith, S. C. Biomineralization of poorly crystalline $\mathrm{Fe}(\mathrm{III})$ oxides by dissimilatory metal reducing bacteria (DMRB). Geomicrobiology Journal 2002, 19, 179-207.

[43] Tosca, N. J.; Ahmed, I. A. M.; Tutolo, B. M.; Ashpitel, A.; Hurowitz, J. A. Magnetite authigenesis and the warming of early mars. Nature Geoscience 2018, 11, 635-639.

[44] Usman, M.; Byrne, J. M.; Chaudhary, A.; Orsetti, S.; Hanna, K.; Ruby, C.; Kappler, A.; Haderlein, S. B. Magnetite and green rust: synthesis, properties, and environmental applications of mixed-valent iron minerals. Chemical Reviews 2018, 118, 3251-3304.

[45] Azoulay, I.; Rémazeilles, C.; Refait, P. Determination of standard Gibbs free energy of formation of chukanovite and Pourbaix diagrams of iron in carbonated media. Corrosion science 2012, 58, 229-236.

[46] Drissi, S. H.; Refait, P.; Abdelmoula, M.; Génin, J. M. R. The preparation and thermodynamic 
properties of $\mathrm{Fe}(\mathrm{II})-\mathrm{Fe}(\mathrm{III})$ hydroxide-carbonate (green rust 1); Pourbaix diagram of iron in carbonate-containing aqueous media. Corrosion science 1995, 12, 2025-2041

[47] Abken H. J.; Tietze, M.; Brodersen, J.; Bäumer, S.; Beifuss, U.; Deppenmeier, U. Isolation and characterization of methanophenazine and function of phenazines in membrane-bound electron transport of Methanosarcina Mazei Gol. Journal of Bacteriology 1998, 180, 2027-2032..

[48] Kip, N.; van Veen, J. A. The dual role of microbes in corrosion. The ISME Journal 2015, 9, 542551.

[49] Videla, H.A.; Herrera, L.K. Microbiologically influenced corrosion: looking to the future. International Microbiology 2005, 8, 169-180.

[50] Kato, S. Microbial extracellular electron transfer and its relevance to iron corrosion. Microbial Biotechnology 2016, 9, 141-148.

[51] Bazylinski, D. A.; Frankel, R. B.; Jannasch, H. W. Anaerobic magnetite production by a marine, magnetotactic bacterium. Nature 1988, 334, 518-519.

[52] Stolz, J. F.; Chang, S, R.; Kirschvink, J. L. Magnetotactic bacteria and single-domain magnetite in hemipelagic sediments. Nature 1986, 321: 849-851.

[53] Lovley, D. R.; Phillips, E. J. P. Availability of ferric iron for microbial reduction in bottom sediments of the freshwater tidal Potomac River. Applied and Environmental Microbiology 1986 $52,751-757$.

[54] Tang, J.; Zhuang, L.; Ma, J.; Tang, Z.; Yu, Z.; Zhou, S. Secondary mineralization of ferrihydrite affects microbial methanogenesis in Geobacter-Methanosarcina cocultures. Applied and Environmental Microbiology 2016, 82, 5869-5877.

[55] Coker, V. S.; Bell, A. M. T.; Pearce, C. I.; Pattrick, R. A. D.; van der Laan, G.; Lloyd, J. R. Time-resolved synchrotron powder X-ray diffraction study of magnetite formation by the Fe(III)-reducing bacterium Geobacter sulfurreducens. American Mineralogist, 2008, 93, 540547.

[56] Roh, Y.; Gao, H.; Vali, H.; Kennedy, D. W.; Yang, Z. K.; Gao, W.; Dohnalkova, A. C.; Stapleton R. D.; Moon J. W.; Phelps, T. J.; Fredrickson, J. K.; Zhou, J. Metal reduction and iron biomineralization by a psychrotolerant Fe(III)-reducing bacterium, Shewanella sp. strain PV-4. Applied and Environmental Microbiology 2006, 72, 3236-3244.

[57] Bharde, A.; Rautaray, D.; Bansal, V.; Ahmad, A.; Sarkar, I.; Yusuf, S. M.; Sanyal, M.; Sastry, M. Extracellular biosynthesis of magnetite using fungi. Small 2006, 2, 135-141.

[58] Kato, S.; Hashimoto, K.; Watanabe, K. Microbial interspecies electron transfer via electric currents through conductive minerals. Proceedings of the National Academy of Sciences of the United States of America, 2012, 109, 10042-10046.

[59] Aulenta, F.; Rossetti, S.; Amalfitano, S.; Majone, M.; Tandoi, V. Conductive magnetite nanoparticles accelerate the microbial reductive dechlorination of trichloroethene by promoting interspecies electron transfer processes. ChemSusChem 2013, 6, 433-436.

[60] Kouzuma, A.; Kato, S.; Watanabe, K. Microbial interspecies interactions: recent findings in syntrophic consortia. Frontiers in Microbiology 2015, 6, 477, 1-8.

[61] Kasten, S.; Freudenthal, T.; Gingele, F. X.; Schulz, H. D. Simultaneous formation of iron-rich layers at different redox boundaries in sediments of the Amazon deep-sea fan. Geochimica et Cosmochimica Acta, 1998, 62, 2253-2264.

[62] Riedinger, N.; Pfeifer, K.; Kasten, S.; Garming, J. F. L.; Vogt, C.; Hensen, C. Diagenetic alteration of magnetic signals by anaerobic oxidation of methane related to a change in sedimentation rate. Geochimica et Cosmochimica Acta, 2005, 69, 4117-4126.

[63] Lefevre, E.; Bossa, N.; Wiesner, M. R.; Gunsch, C. K. A review of the environmental 
implications of in situ remediation by nanoscale zero-valent iron (nZVI): behavior, transport and impacts on microbial communities. Science of the Total Environment 2016, 565, 889-901.

[64] Xie, Y.; Dong, H.; Zeng, G.; Tang, L.; Jiang, Z.; Zhang, C.; Deng, J.; Zhang, L.; Zhang, Y. The interactions between nanoscale zero-valent iron and microbes in the subsurface environment: a review. Journal of Hazardous Materials 2017, 321, 390-407.

[65] Kumar, N.; Omoregie, E. O.; Rose, J.; Masion, A.; Lloyd, J. R.; Diels, L.; Bastiaens, L. Inhibition of sulfate reducing bacteria in aquifer sediment by iron nanoparticles. Water Research 2014, 51, 64-72.

[66] Tilston, E. L.; Collins, C. D.; Mitchell, G. R.; Princivalle, J.; Shaw, L. J. Nanoscale zerovalent iron alters soil bacterial community structure and inhibits chloroaromatic biodegradation potential in Aroclor 1242-contaminated soil. Environmental Pollution 2013, 173, 38-46.

[67] Auffan, M.; Achouak, W.; Rose, J.; Roncato, M. A.; Chaneac, C.; Waite, D. T.; Masion, A.; Woicik, J. C.; Wiesner, M. R.; Bottero, J. Y. Relation between the redox state of iron-based nanoparticles and their cytotoxicity toward Escherichia coli. Environmental Science \& Technology 2008, 42, 6730-6735.

[68] Lee, C.; Kim, J. Y.; Lee, W. I.; Nelson, K. L.; Yoon, J.; Sedlak, D. L. Bactericidal effect of zerovalent iron nanoparticles on Escherichia coli. Environmental Science \& Technology 2008, 42, 4927-4933.

[69] Xiu, Z.; Jin, Z.; Li, T.; Mahendra, S.; Lowry, G. V.; Alvarez, P. J. Effects of nano-scale zerovalent iron particles on a mixed culture dechlorinating trichloroethylene. Bioresource Technology 2010, 101, 1141-1146.

[70] Barnes, R. J.; Riba, O.; Gardner, M. N.; Singer, A. C.; Jackman, S. A.; Thompson, I. P. Inhibition of biological TCE and sulphate reduction in the presence of iron nanoparticles. Chemosphere 2010, 80, 554-562.

[71] Fajardo, C.; Ortiz, L. T.; Rodriguez-Membibre, M. L.; Nande, M.; Lobo, M. C.; Martin, M. Assessing the impact of zero-valent iron (ZVI) nanotechnology on soil microbial structure and functionality: a molecular approach. Chemosphere 2012, 86, 802-808.

[72] An, Y.; Li, T.; Jin, Z.; Dong, M.; Li, Q.; Wang, S. Decreasing ammonium generation using hydrogenotrophic bacteria in the process of nitrate reduction by nanoscale zero-valent iron. Science of the Total Environment 2009, 407, 5465-5470.

[73] Carpenter, A. W.; Laughton, S. N.; Wiesner, M. R. Enhanced biogas production from nanoscale zero valent iron-amended anaerobic bioreactors. Environmental Engineering Science 2015, 32, 647-655.

[74] Su, C.; Puls, R. W.; Krug, T. A.; Watling, M.T.; O’Hara, S. K.; Quinn, J. W.; Ruiz, N. E. Travel distance and transformation of injected emulsified zerovalent iron nanoparticles in the subsurface during two and half years. Water Research 2013, 47, 4095-4106.

[75] Yang, Y.; Guo, J.; Hu, Z. Impact of nano zero-valent iron (NZVI) on methanogenic activity and population dynamics in anaerobic digestion. Water Research 2013, 47, 6790-6800.

[76] Dubiel, M.; Hsu, C. H.; Chien, C. C.; Mansfeld, F. B,; Newman, D. K. Microbial iron respiration can protect steel from corrosion. Applied and Environmental Microbiology 2002, 68, 1440-1445.

[77] Serrano-Silva, N.; Sarria-Guzman, Y.; Dendooven, L.; Luna-Guido, M. Methanogenesis and methanotrophy in soil: a review. Pedosphere 2014, 24, 291-307.

[78] Ferry, J. G.; Lessner, D. J. Methanogenesis in marine sediments. Annals of the New York Academy of Sciences 2008, 1125, 147-157.

[79] van den Berg, L. Developments in methanogenesis from industrial waste water. Canadian Journal of Microbiology 1984, 30, 975-990. 
[80] Tabatabaei, M.; Rahim, R. A.; Abdullah, N.; Wright, A. D. G.; Shirai, Y.; Sakai, K.; Sulaiman, A.; Hassan, M. A. Importance of the methanogenic archaea populations in anaerobic wastewater treatments. Process Biochemistry 201, 45, 1214-122. 